\title{
Announcements
}

Neuropsychobiology

\section{World Congress of Psychiatry}

Hamburg, August 6-11, 1999

For further information contact the congress office:

CPO HANSER Service

P.O. Box 1221

D-22882 Barsbüttel (Germany)

Fax +49 4067032 83, E-Mail cpo@wpa-hamburg.de

http://www.wpa-hamburg.de

\section{2th ECNP Congress}

London, September 21-25, 1999

Organising Secretariat:

Congrex Holland BV/Concorde Services Ltd c/o P.O. Box 302

1000 AH Amsterdam (The Netherlands)

Tel. +31 205040 207, Fax +31 205040225

E-Mail ecnp@congrex.nl

\section{KARGER}

(C) 1999 S. Karger AG, Basel

Fax +41613061234

E-Mail karger@karger.ch

www. karger.com
Accessible online at: http://BioMedNet.com/karger 